\title{
HUBUNGAN PEKERJAAN IBU DENGAN KEMAMPUAN 8 INDIKATOR PERILAKU HIDUP BERSIH DAN SEHAT PADA SISWA MADRASAH IBTIDAIYAH KECAMATAN MOJOROTO KOTA KEDIRI
}

\author{
Heny Kristanto $^{1}$, Sucipto $^{2}$, Didik Susetyanto Atmojo ${ }^{3}$ \\ Akademi Keperawatan Dharma Husada Kediri ${ }^{1,2,3}$ \\ email: hanssaviera@yahoo.co.id
}

\begin{abstract}
Strategic efforts to improve the quality of Indonesian people with various approaches have been carried out to improve public health, including the implementation of health services in schools. However, health problems related to clean and healthy lifestyle are still the main health problems in Indonesia. The school community has an important role in efforts to improve and improve the health status of the community, thus if health promotion is not done well, it will have an impact on knowledge of PHBS, and ultimately reduce the quality of health and academic achievement of children. In children can be started from the family environment. However, the ability of mothers to carry out education to introduce and teach healthy lifestyles in children is certainly influenced by many factors; one of them is work, and mother's knowledge. The research design used was the design of Analytic Correlation with a Cross Sectional approach in the Madrasah Ibtidaiyah, Mojoroto District, Kediri City. Data analysis using statistical tests with Ordinal Regression with values. $P=0.032$, shows the work of mothers have an important role in instilling PHBS in family members, especially in children. Working mothers, should understand the important role as educators and then be able to set aside time to be able to instill PHBS to children
\end{abstract}

Keywords: mother's work, 8 PHBS indicators

\section{PENDAHULUAN}

Ibu mempunyai peran yang sangat penting untuk membangun perilaku hidup sehat dalam keluarga dan memelihara kesehatan keluarga. Ibu memainkan peran penting sebagai pemberi asuhan primer untuk semua anggota keluarga. Dalam menjalankan peran pencegahan primer, ibu dalam suatu keluarga memiliki peran yang sangat penting. Kebanyakan ibu di masyarakat Indonesia memiliki waktu yang lebih banyak dalam mendidik anak termasuk pendidikan kesehatan. Berkenaan dengan pendidikan kesehatan dalam keluarga, satu penelitian tentang Peran Ibu Dalam Pendidikan Anak, didapatkan hasil bahwa kegiatan ibu memberikan contoh baik 27,2 \%, menanamkan disiplin 22,8 \%. ( Pidarta Made, 1997). Pada ibu yang tidak bekerja tentunya memiliki waktu yang lebih banyak untuk memberikan pendidikan dan menanamkan kebiasaan pada anak untuk erperilaku sehat dibandingkan dengan ibu yang bekerja. 
Perilaku Hidup Bersih dan Sehat (PHBS) merupakan suatu bentuk pola kebiasaan untuk mempertahankan dan meningkatkan status kesehatan pribadi dan lingkungan. Pola kebiasaan dalam ber PHBS dapat mulai dikenalkan pada anak di lingkungan keluarga. Dengan demikian keluarga memiliki peran yang sangat penting dalam pencegahan primer terhadap terjadinya masalah kesehatan pada anggota keluarga. (Friedman M.M. 2002)

Keberhasilan untuk mengenalkan dan mengajarkan pola hidup sehat pada anak dapat dimulai dari lingkungan keluarga. Akan tetapi kemampuan ibu dalam melaksanakan pendidikan untuk mengenalkan dan mengajarkan pola hidup sehat pada anak, tentunya dipengaruhi oleh banyak faktor; diantaranya adalah pendidikan ibu, pekerjaan, dan pengetahuan ibu. Penelitian yang dilakukan Damiyanti (2014) didadapatkan hasil hampir seluruh responden (94,1\%) ibu rumah tangga yang memiliki pengetahuan Baik terhadap PHBS menerapkan PHBS pada tatanan rumah tangga, sedangkan pada ibu yang berpengetahuan rendah tentang PHBS, hampir seluruh ibu ( 85,7 \%) tidak menerapkan PHBS di tatanan rumah tangga. (Damiyanti, 2014)

\section{METODE PENELITIAN}

Penelitian ini menggunakan desain Deskriptif Analitik. Dalam penelitian ini, sampel penelitian adalah siswa kelas 3 pada 7 Madrasah Ibtidaiyah di Kec. Mojoroto Kota Kediri . Waktu penelitian selama 4 bulan (Juli sampai dengan Oktober 2018). Tempat penelitian adalah 7 Madrasah Ibtidaiyah di Kec. Mojoroto Kota Kediri. Pengujian statistic menggunakan Regresi Ordinal.

\section{HASIL DAN PEMBAHASAN}

Berdasarkan hasil penelitian, karakteristik responden diklasifikasikan meliputi jenis kelamin, terpajan informasi, lingkungan rumah, pengalaman / kebiasaan PHBS di rumah.

Tabel 1 Karakteristik Responden

\begin{tabular}{lcc}
\hline KarakteristikResponden & $\mathrm{n}$ & $\%$ \\
\hline Jenis Kelamin & & \\
a. Laki - laki & 37 & 41,2 \\
b. Perempuan & 50 & 58,8 \\
\hline Terpajan Informasi & & \\
a. Pernah & 42 & 49,4 \\
b. Tidak Pernah & 45 & 40,6 \\
\hline
\end{tabular}




\begin{tabular}{lll}
\hline Lingkungan Rumah & \\
a. Pedesaan & 12 & 13,8 \\
b. Perkampungan & 16 & 18,4 \\
c. Perkotaan & 59 & 67,8 \\
\hline Pengalaman / Kebiasaan PHBS di Rumah & & \\
a. Ada & 68 & 80 \\
b. Tidak & 17 & 20 \\
\hline
\end{tabular}

Berdasarkan Tabel 1. dinyatakan bahwa lebih dari setengah 58,8\% responden berjenis kelamin perempuan, hampir setengah $49,4 \%$ pernah terpajan informasi, lebih dari setengah 67,8\% tinggal di lingkungan perkotaan dan sebagian besar $80 \%$ memiliki pengalaman / kebiasaan PHBS di tatanan rumah tangga.

Tabel 2 Pekerjaan Ibu

\begin{tabular}{lll}
\hline Pekerjaan Ibu & $\mathrm{n}$ & $\%$ \\
\hline Bekerja & 23 & 27,1 \\
Tidak Bekerja / Ibu RT & 64 & 72,9 \\
\hline
\end{tabular}

Berdasarkan Tabel 2. dinyatakan bahwa sebagian besar 72,9 \% ibu responden penelitian adalah ibu yang tidak bekerja atau sebagai ibu rumah tangga.

Tabel 3. Hasil Analisa Statistik

Parameter Estimates

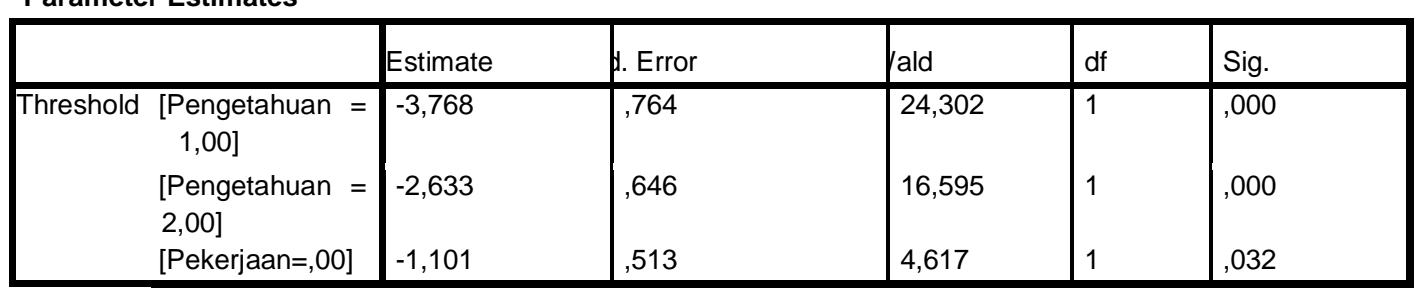

Berdasarkan penelitian yang dilaksanakan pada siswa MI di kecamatan Mojoroto Kota Kediri, tentang “ Hubungan Pekerjaan Ibu dengan Kemampuan 8 indikator PHBS Siswa MI", didapatkan hasil bahwa kemampuan siswa untuk 8 indkator PHBS dipengaruhi oleh pekerjaan ibu yang ditunjukan hasil uji statistik dengan nilai signifikan 0,032 .

Seiring dengan perkembangan zaman, perempuan bekerja merupakan suatu hal yang biasa baik bekerja di luar maupun di dalam rumah. Beberapa perempuan yang bekerja di luar rumah, bahkan mampu menduduki posisi penting dalam beberapa jabatan baik di sektor swasta maupun di pemerintahan. Keterlibatan perempuan untuk bekerja, dikarenakan keinginan mereka untuk mencukupi kebutuhan perekonomian keluarga ( Midawati. 2016). 
Menurut Handayani, seorang perempuan yang bekerja, memiliki peran ganda yang harus dijalankan pada saat bersamaan. (Handayani, Maulia, \& Yulianti. 2012)

Peran ganda yang dilakukan oleh ibu yang bekerja, seringkali menimbulkan kondisi stress dan bahkan memunculkan konflik baik personal ibu maupun dalam keluarga.

Kenyataan yang sering didapatkan pada ibu yang bekerja, baik di dalam maupun di luar rumah, adalah pengabaian dalam pendidikan anak termasuk didalamnya adalah menanamkan untuk menjaga kebersihan tubuh dan Perilaku Hidup Bersih dan Sehat (PHBS).

Penelitian tentang Penyuluhan Sebagai Upaya Penguatan Peran Ibu Dalam Implementasi Perilaku Hidup Bersih dan Sehat didapatkan hasil bahwa setelah dilakukan penguatan berdasarkan parameter yang telah ditetapkan, bahwa untuk meningkatkan pengetahuan ibu, perlu dilakukan penguatan dengan cara penyuluhan. (Ari Sulistyawati, Nova Listiana. 2015).

Sejalan dengan hasil dari beberapa penelitian tersebut di atas, bahwa ibu memiliki peran penting dalam pendidikan kesehatan dalam keluarga, terutama dalam menanamkan PHBS kepada anak. walaupun kemampuan anak dalam 8 indikator PHBS tidak hanya terbatas pada ibu bekerja atau tidak bekerja, akan tetapi bahwa pendidikan anak dapat dimulai dari lingkungan keluarga. Pada ibu bekerja, terutama yang bekerja di luar rumah, memiliki sedikit waktu untuk dapat memberikan pendidikan dan pendampingan pada anak untuk melaksanakan PHBS.

\section{KESIMPULAN}

Bahwa ibu memiliki peran penting dalam menanamkan PHBS pada anggota keluarga, terutama pada anak. Dengan demikian, maka pada ibu - ibu yang bekerja, baik di dalam maupun di luar rumah, selayaknya meahami peran penting sebagai pendidik dan selanjutnya dapat menyisihkan waktu untuk dapat menanamkan PHBS kepada anak.

\section{DAFTAR PUSTAKA}

Ari Sulistyawati, Nova Listiana (2015) Penyuluhan Sebagai Upaya Penguatan Peran Ibu Dalam Implementasi Perilaku Hidup Bersih dan Sehat. Jurnal.akbiduk.ac.id

Damiyanti, S. Crisni, H. 2014. Hubungan Pengetahuan Ibu Rumah Tangga dan Peran Kader Dengan PHBSDalam Rumah Tangga Di Kelurahan Laing 
Wilayah Kerja Puskesmas Nan Balimo Kecamatan Tanjung Harapan Kota Solok. Tahun 2014. LPPM Stikes Yarsi.

Departemen Kesehatan RI, 2007. Buku Saku Rumah Tangga Sehat dengan PHBS. Pusat Promosi Kesehatan. Jakarta

Friedman M.M. 2002. Buku Ajar Keperawatan Keluarga, Riset Teori \& Praktik. EGC. Jakarta

Handayani, A., Maulia, D., \& Yulianti, P.D. 2012. Pengaruh Konflik Peran Ganda Terhadap Kinerja Guru. Penelitian Kinerja Untuk Peningkatan Profesionalisme Guru Berkelanjutan. http://prosiding.upgrismg.ac.id/

Kementrian Kesehatan. 2011. Panduan Peningkatan PHBS di Rumah Tangga. Pusat Promosi Kesehatan. Departemen Kesehatan RI. Jakarta

Midawati. 2016. Faktor - Faktor yang Menghalangi Wanita Sistem Nasab Ibu Berniaga Sendiri di Pasar - Pasar Rembau Negeri Sembilan Kafaah : Journal of Gender Studies.

Notoatmodjo S. 2010. Metodologi Penelitian Kesehatan. Rineka Cipta. Jakarta

Pidarta Made. 1997. Peran Ibu Dalam Pendidikan Anak. Jurnal Ilmu Pendidikan. Jilid 4. Nomor 4 